\title{
General Psychiatry Study on the combination of brief psychodynamic psychotherapy with Viagra in the treatment of non- organic ED
}

\author{
Zhihang Zhang, ${ }^{1}$ Xiang Gao, ${ }^{2}$ Ying Zhou, ${ }^{3}$ Chao Yu, ${ }^{2,4}$ Jittikorn Pimolsettapun, ${ }^{1}$ \\ Libin Yang, ${ }^{1}$ Youkang Zhao ${ }^{1}$
}

To cite: Zhang Z, Gao X, Zhou Y, et al. Study on the combination of brief psychodynamic psychotherapy with Viagra in the treatment of non-organic ED. General Psychiatry 2020;33:e100184. doi:10.1136/ gpsych-2019-100184

$\mathrm{ZZ}$ and $\mathrm{XG}$ are joint first authors.

Received 25 November 2019

Revised 23 May 2020

Accepted 15 June 2020

Check for updates

C Author(s) (or their employer(s)) 2020. Re-use permitted under CC BY-NC. No commercial re-use. See rights and permissions. Published by BMJ.

${ }^{1}$ Sexual Medicine and Andrology Department, Long Hua Hospital, Shanghai, China

${ }^{2}$ Shanghai Yizhi Institute of Applied Psychology, Shanghai, China

${ }^{3}$ Shanghai Huangpu District Mental Health Center, Shanghai, China

${ }^{4}$ Urology and Andrology Department, Longhua Hospital Affiliated to Shanghai University of TCM, Shanghai, China

Correspondence to

Dr Chao Yu;

yubeyond@163.com

\section{ABSTRACT}

Background Erectile dysfunction (ED) has gradually become an important issue that seriously affects the quality of life of Chinese men. In addition to classic oral medications, psychotherapeutic interventions are increasingly being used in the treatment of ED.

Aim This study aims to investigate the clinical efficacy of brief psychodynamic psychotherapy (BPP) plus Viagra in the treatment of non-organic ED.

Methods We initiated this study via a controlled, prospective experimental design with initial optimal efficiency standard greater than $10 \%$. On the standard, 63 patients were enrolled who were assigned to control or treatment group. The control group (including 33 cases) received Viagra treatment for 2 months, and the treatment group (including 30 cases) was cured with BPP plus Viagra. After the treatments, the clinical efficacy was assessed using the International Erectile Function Index (IIEF-5) score, the Self-rating Anxiety Scale (SAS), Sexual Satisfaction (SS) score and Erection Hardness Score (EHS). Results In the comparison of efficacy, pretreatment and post-treatment within each group, the two groups showed improvements in IIEF, SAS scores, SS, and EHS (treatment group: $\mathrm{P}_{\| E F}<0.001, \mathrm{P}_{S A S}<0.001, \mathrm{P}_{S S}<0.001, \mathrm{P}_{\mathrm{EHS}}<0.001$; control group: $P_{\| E F}<0.001, P_{S A S}<0.001, P_{S S}<0.001$ $\left.P_{E H S}<0.001\right)$. Furthermore, the treatment group presented better performances in IIEF ( $p=0.040)$, SAS $(p=0.006)$, SS scores $(p=0.045)$ and EHS $(p=0.041)$ than the control group.

Conclusion The combination of BPP with Viagra has positive effect on the treatment of non-organic ED.

\section{INTRODUCTION}

With the accelerated development of China's society and economy, people are increasingly eager to pursue happiness in their lives. Erectile dysfunction (ED) is one of the main diseases, which disturbs the happiness of many families. ${ }^{1}$ Sildenafil, a representative drug of phosphodiesterase 5 (PDE5) inhibitor, can improve the dysfunctions and quality of sexual life in patients with ED. ${ }^{2}$ From the perspective of couple psychodynamics, ED may represent a neurotic solution for deep relationship conflicts, lack of communication or a power struggle, and therefore deserves further exploration. In the treatment of ED, the unique value of psychodynamic psychotherapy is far more than the improvement of symptoms. Psychodynamic psychotherapy works on the symptoms, and explores the emotional conflicts, defence mechanisms, developmental deficits and personality structure underlying the symptoms to work through them. In recent years, we have adopted a combination of brief psychodynamic psychotherapy (BPP) and traditional medicines to cure non-organic ED. BPP, which emphasises the continuity of development in a patient's personality, is developed on the basis of traditional long-term psychodynamic psychotherapy (LTPP) and psychoanalysis. Moreover, when encountering a psychodynamic conflict, therapists can quickly make adjustments through a short, effective and operative technique. This attempt to apply psychological intervention to the treatment of clinical diseases has achieved some certain curative effect, which has made it useful for the combination of conventional medicines and psychological interventions for sexual dysfunction.

\section{MATERIALS AND METHODS \\ Participants \\ Diagnostic criteria}

The diagnosis of ED is consistent with the relevant criteria in the "Guidelines for the Andrology Diagnosis and Treatment of Erectile Dysfunction's: 'International Erectile Function Index' (IIEF-5) score $^{3}$ of $<22$, penis continues to (at least 6 months) fail to reach and maintain a full erection for a satisfactory sexual life. Non-organic criteria: organic impotence was excluded by using penile 
blood vessels and neurological function tests (penile blood flow map impedance method and penile dorsal nerve conduction velocity), sex hormone tests (blood testosterone, luteinising hormone, follicle-stimulating hormone, prolactin), B ultrasound (testis and spermatic cord), clinical symptoms of testis, spermatic cord and physical examinations. ${ }^{4}$

\section{Inclusion criteria}

The participants had to fulfill the following inclusion criteria: (1) participants who met all the above diagnostic criteria; (2) participants who were 25-45 years old, for ethical reasons the selected patients were all married; (3) participants whose course of disease was more than 6 months; (4) ED was not due to an organic disease or an accompanying symptom from another disorder from the Diagnostic and Statistical Manual of Mental Disorders, Fourth Edition, Text Revision (DSM-IV-R) prescribed as an axis I mental disorder. Patients with or without other sexual dysfunction (such as premature ejaculation, ejaculation dysfunction), and whose spouse does not have the axis I mental illness prescribed by DSM-IV-R, except sexual dysfunction; (5) without marriage (divorce) pressure, both couples were willing to participate in treatment without any external motivation or other secondary gains; ${ }^{45}$ (6) Patients had strong motivation to seek treatment, and could detect their own conflict. Their relational conflict and other psychological conditions were suitable for BPP. ${ }^{67}$

\section{Exclusion criteria}

Participants were excluded according to the following exclusion criteria: (1) participants who received other treatments in the past 7 days that might interfere with the assessment of efficacy; (2) participants who suffered obvious genital malformation or reproductive system infection; (3) participants with severe depression and psychosis, personality disorders with dissociative and denial defence mechanisms; (4) participants who suffered from a serious primary cardiovascular, liver, kidney or haematopoietic system disease; (5) participants who were allergic to the drugs used in this study; (6) participants who experienced a history of active infectious diseases; (7) participants who were treated under non-standard provisions, or provided incomplete data, which might affect the efficacy or safety judgement.

\section{General information}

Patients were recruited through advertising and from the outpatients who were recruited from the hospital. If a participant had a serious adverse event during the course of treatment, the physician decided whether to suspend the observation based on the condition. Initially, 83 cases meeting the related requirements were collected, who were admitted to the departments of urology and sexual medicine in our hospital from August 2014 to March 2017 (excluding the patients who had serious primary diseases of blood vessels, liver, kidney and haematopoietic system).
According to the treatment intention, the patients were assigned into control group (42 cases) or treatment group (41 cases). During the study, 20 patients withdrew from the trial for the following reasons: (a) worrying about confidentiality; (b) receiving other treatments without permission and not taking drugs under regulations. Finally, there were 63 patients who met the requirements, 30 cases for the treatment group and 33 cases for the control group. Two patients in the treatment group and three in the control group had a long-term smoking history, and no one had a long-term history of alcoholism and other substance addiction. The mean (SD) age of the treatment group was 34.84 (5.97), the mean (SD) disease duration was 6.97 (1.43) months, the mean (SD) SS score was $1.23(0.86)$. The mean (SD) age of the control group was 33.98 (6.04); the mean (SD) duration of disease was 6.86 (1.58) months and the mean Sexual Satisfaction (SS) score was $1.18(0.85)$. There was no statistically significant difference in baseline data between the two groups which were comparable, as demonstrated in figure 1.

\section{Therapeutic methods}

\section{The control group}

Sildenafil citrate (Pfizer Pharmaceutical, H20020528) was orally taken (100 mg each time) within 1-2 hours before sexual activity, taken as needed. The course of treatment was 2 months. During the course, the patients took sildenafil a total of four to eight times. ${ }^{8}$

\section{The treatment group}

The treatment group was given the same drug as the control in combination with BPP.

Individualized treatment was adopted. Each treatment lasted 1 hour, two times a week and the treatment was kept up for about 2-3 months or so, a total of 16-24 times. The therapists are all professional practitioners who have been in practice for more than 5 years, and all have the qualifications of national level two psychological counsellors and psychotherapists. They accepted long-term supervision from mentors of the psychodynamic (psychoanalysis) school (see the appendix of biography).

The general process of BPP is this ${ }^{9}{ }^{10}$ : In the initial phase (one to three sessions, with the patient and his wife required to attend the first session), intake is conducted and rapport is developed between the doctor and patient. Sex education is given to the patient, as well as focusing on gaining the patient's cooperation and increasing their confidence to overcome this disease. The relationship episode (RE: it refers to a story / example that patient tells the therapist about his / her communication with others. It usually consists of three parts: wish, response from the other, response from the self) is recorded in the conversation with the patient, as well as summarising the focal conflict from 5 to $7 \mathrm{RE}$ and emphasising that understanding the focal conflict of the client is common in their lives. In intermediate stage (a total of 14-18 sessions), patients take a comfortable sitting or lying position and free associate. Then, the therapist tries to 


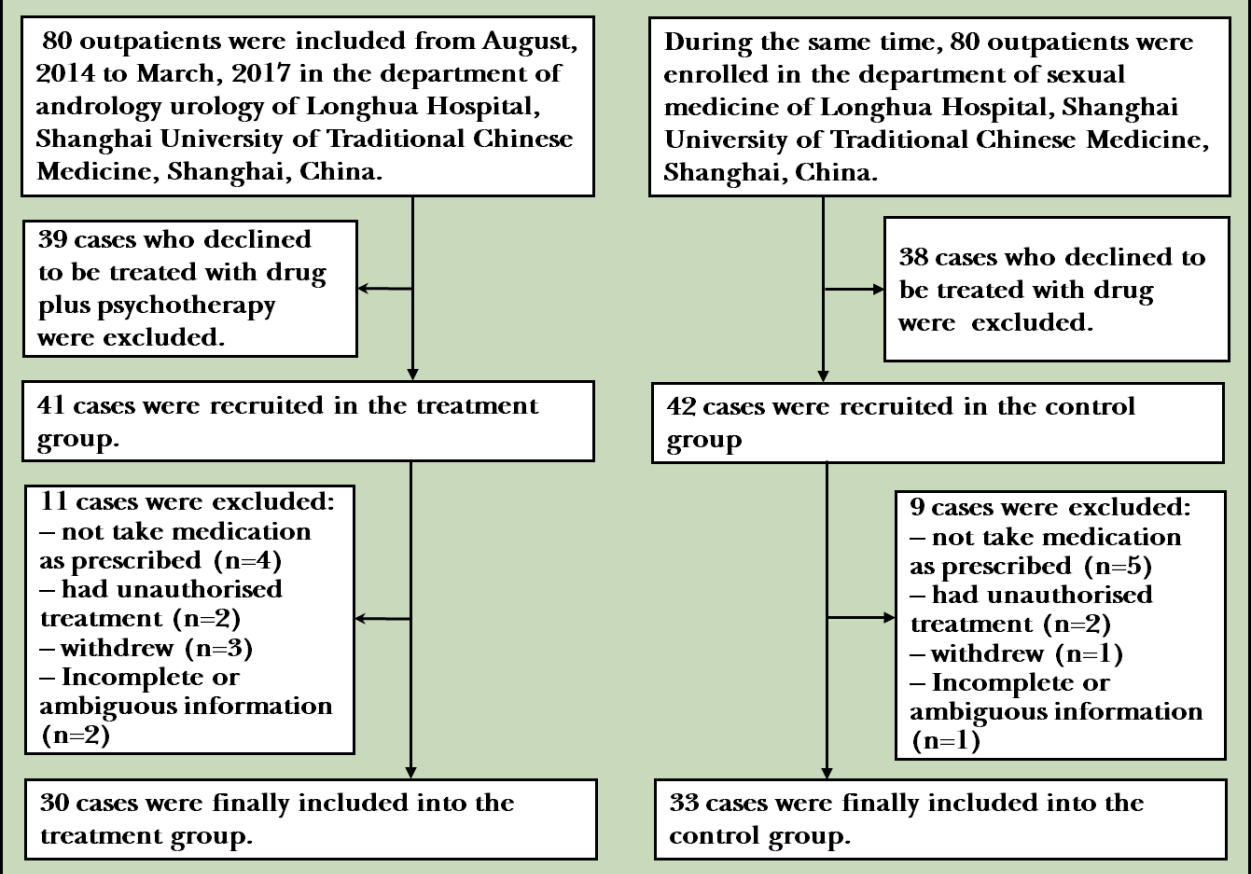

Figure 1 Flowchart of the study.

analyse the patient's subconscious behavioural motives, deal with the patients's 'transference' and use psychoanalysis technique to perform the corresponding psychological treatments. These include encouraging the patients to speak out about the problems after the relationship is strengthened. The therapist needs to listen to the patients' problems with empathy. Dream interpretation techniques can be used for refractory patients if necessary. Helping patients to recognise and clear the focal conflict and its contact with previous experience, and considering using a new way of thinking or performance, and direct support can also be used to explain it. When the therapist de-sickens (treat the patient in the way of a normal person), and runs through the entire treatment process in a highly receptive manner, so that the patient's psychological energy flows without paying attention to the symptoms, and they will have more psychological energy to face the treatment. They will accept the conflict as an existence in the past and real experience, rather than as a symptom to avoid or try to eliminate it. Finally, the patients reache the stage of working through and making a new change. In ending stages of treatment (one to three session), the focus is on termination. The patient must be made to understand that the end of treatment means a healthier, more independent and self-regulating life that is less dependent on the therapist, rather than thinking sessions are ending because the therapist is disgusted with or estranged from him. If necessary, the therapist will still be available to help, either by phone or through an occasional booster session. Unlike traditional LTPP that makes a broad personality analysis for patients, BPP focuses on the changes of a problem or features, not extensive personality analysis. ${ }^{10}$

\section{Observation items and methods for efficacy evaluation}

Before and after treatment, the relevant staff (graduate students) were responsible for the statistics and records of the pretrial and post-trial scales and relevant laboratory tests.

\section{Erectile function score}

Before and after treatment, the 'International Erectile Function Index (IIEF-5) ${ }^{4}$ with a reliability of $0.91-0.96$ and validity of 0.75 was used to evaluate the patient's erectile function. ${ }^{5}$ The fifth question of the scale is the evaluation of sexual satisfaction.

\section{Self-rating Anxiety Scale}

Self-rating Anxiety Scale (SAS) ${ }^{4} 8$ (reliability 0.824, validity $0.72^{9}$ ) scores were adopted before and after treatment to mainly evaluate related anxiety.

\section{Erection Hardness Score}

The international four-level hardness model: level I, penis volume increases, hardness is poor (like tofu); level II, it is hard, but cannot be inserted into the vagina (like a peeled banana); level III, it can be inserted into the vagina, but not completely hard (like a peeled banana); level IV, it is completely hard and erect (like a cucumber).

\section{Security}

Blood routine, liver function, renal function and blood pressure were measured before and after treatment. Drug-related adverse reactions were observed during the test. 


\section{Methods for efficacy evaluation}

The IIEF- 5 score is divided into four grades: severe ED is less than 7; 8-11 for moderate ED; $12-21$ for mild ED; $\geq 22$ for normal. The efficacy evaluation grades are as follows: full recovery, IIEF- 5 score $\geq 22$ after treatment; markedly effective, IIEF- 5 score after treatment improves two grades but not up to full recovery; effective, IIEF-5 score increased one grade after treatment; invalid, IIEF-5 score after treatment does not increase a grade. Effectiveness rate is calculated by (full recovery+significant improvement+effective) / total number of cases $\times 100 \%{ }^{4}$

\section{Statistical analysis}

The data were statistically analysed using SPSS V.19.0 software, and were expressed as mean(SD); the grade was evaluated by Ridit. All quantitative variables were analysed using two-tailed t-test, and statistical significance was set at $\mathrm{p}<0.05$.

\section{RESULTS}

At the end of the course of treatment, the mean (SD) number of times taking sildenafil was 6.53 (1.38) in the treatment group and 6.44 (1.52) in the control group. There was no statistical difference between the two groups ( $\mathrm{p}=0.810)$, that is, the total number of times taking sildenafil in the treatment group and the control group was the same.

\section{Treatment of ED}

A total of 63 people participated in the study. These participants were divided into the control group $(n=33)$ and treatment group $(n=30)$. After 2 months of treatment, the treatment group showed a better curative effect than the control group $(\mathrm{p}=0.046)$ (see table 1$)$.

\section{Changes in IIEF-5, SAS and SS scores}

There were no significant differences in IIEF-5, SAS and SS scores between the two groups before treatment $\left(\mathrm{P}_{\text {IIEF }}=0.745 ; \mathrm{P}_{\mathrm{SAS}}=0.712 ; \mathrm{P}_{\mathrm{SS}}=0.803\right)$. In comparison with the efficacy of pretreatment and post-treatment within each group, the two groups showed improvements in IIEF, SAS and SS scores (treatment group: $\mathrm{P}_{\text {IIEF }}<0.001, \quad \mathrm{P}_{\mathrm{SAS}}<0.001, \quad \mathrm{P}_{\mathrm{SS}}<0.001 ;$ control treatment group: $\left.\mathrm{P}_{\text {IIEF }}<0.001, \mathrm{P}_{\mathrm{SAS}}<0.001, \mathrm{P}_{\mathrm{SS}}<0.001\right)$. The IIEF-5, SAS and SS scores of the treatment group were better than the control group after treatment $\left(\mathrm{P}_{\mathrm{IIEF}}=0.04, \mathrm{P}_{\mathrm{SAS}}=0.006\right.$, $\mathrm{P}_{\mathrm{SS}}=0.045$ ) (see table 2).

\section{Changes in Erection Hardness Score}

There was no significant difference between the two groups before treatment $(\mathrm{p}=0.695)$. After 2 months of treatment, 27 cases in the treatment group and 26 cases in the control group reached level III or above. There was a significant difference between the two groups after the treatment ( $\mathrm{p}=0.041$ ), and the treatment group was better than the control group (see table 3 ).

\section{Safety comparison}

In the treatment group, one patient presented mild urinary tract irritation symptoms such as frequent urination and urgency, which was not treated and did not affect the testing and observation. In the control group, one patient showed red-green parallax, which was relieved by himself. Blood routine, liver function, renal function and blood pressure of the two groups before and after treatment were not significantly abnormal.

\section{DISCUSSION}

\section{Main findings}

ED in the past, called impotence, refers to the man in continuous sexual stimulation of the penis that cannot achieve or maintain enough hardness to complete satisfactory sexual intercourse. As a disorder with a high prevalence and incidence, ED negatively affects the quality of life and psychological health of patients and their partners. The normal erectile function of the penis needs the coordination of vascular, nerve, hormone, spongy body and other factors, including psychological factors, among which the abnormality of any of these can lead to ED. ED is usually classified into three groups according to the causes: organic ED, psychological ED and mixed ED. Aetiological studies of ED found that approximately $39 \%$ of patients with ED had non-organic ED. Psychological stress is closely related to $\mathrm{ED}$, such as daily marital disharmony, asymmetric or lack of sexual knowledge, bad sexual experience, work or financial pressure, incorrect understanding of media, fear of illness, adverse drug reactions, and so on. ${ }^{1011}$

The introduction of oral drugs such as sildenafil has radically changed the treatment of $\mathrm{ED}$, reducing the use of other treatments such as medicated urethral system for erection, vacuum constrictor, vascular surgery and penile prosthesis. Sildenafil is traditionally taken as needed. Clinical studies have shown that continuous daily administration of $100 \mathrm{mg}$ of sildenafil can significantly improve the IIEF score of patients and sexual quality of life for

Table 1 Effects of erectile function after treatment

\begin{tabular}{llllll} 
Groups & Fully recovered & Significantly effective & Moderately effective & Ineffective & Total efficiency (\%) \\
\hline Treatment group $(n=30)$ & 6 & 5 & 12 & 7 & $23(76.6)$ \\
Control group $(n=33)$ & 2 & 4 & 13 & 14 & $19(57.6)$ \\
\hline
\end{tabular}

The total efficiency between the two groups showed significant difference with $p=0.046$. 


\begin{tabular}{|c|c|c|c|c|}
\hline Groups & & IIEF & SAS & SS \\
\hline \multirow{2}{*}{$\begin{array}{l}\text { Treatment group } \\
(\mathrm{n}=30)\end{array}$} & Before treatment & $11.17(3.45)$ & 58.27 (7.97) & $1.23(0.86)$ \\
\hline & After treatment & $18.23(4.17)^{\star} \dagger$ & $40.90(12.35)^{*} \dagger$ & $2.90(1.06)^{*} \dagger$ \\
\hline \multirow{2}{*}{$\begin{array}{l}\text { Control group } \\
(n=33)\end{array}$} & Before treatment & $10.88(3.53)$ & $58.88(8.50)$ & $1.18(0.85)$ \\
\hline & After treatment & $16.03(4.78)^{\star}$ & $48.87(11.45)^{\star}$ & $2.30(1.10)^{\star}$ \\
\hline
\end{tabular}

†Comparison between pretreatment and post-treatment within each group. The IIEF-5, SAS and Sexual Satisfaction scores of treatment group were better than the control group after treatment, and the difference was statistically significant $\left(P_{\text {IIEF }}=0.04, P_{S A S}=0.006, P_{S S}=0.045\right)$. ${ }^{*} \mathrm{P}<0.001$.

IIEF, International Erectile Function Index; SAS, Self-rating Anxiety Scale; SS, Sexual Satisfaction.

both men and women, as well as improve the endothelial diastolic function and erectile hardness of patients with ED, and improve tolerance of patients with ED. ${ }^{12-15}$ It has generally been accepted that patients presenting with ED are treated with sildenafil regardless of aetiology. However, a reasonable share of sildenafil non-responders have a non-organic ED. Unfortunately, studies on the aetiology of ED found that about 39\% of patients with ED belong in the non-organic category. From a biopsychosocial perspective, the effects of vascular and hormonal mechanisms in ED are limited and transient, only by providing patients with an integrated medical and psychological approach could the effectiveness of treatment be increased.

Rosen reported that sexual psychotherapy (SP) in combination with sildenafil is effective for patients who do not respond to sildenafil monotherapy. ${ }^{16}$ In our view, medical and psychosexual therapies are not indeed two distinct therapeutic entities to be used in different clinical settings, but are two important tools to be simultaneously considered (and often simultaneously employed) to fully rescue the sexual satisfaction of the couple. SP should be considered a useful chance on all occasions. When non-organic causes are predominant, SP could help in solving the problem. Conversely, when ED is mainly a symptom of an organic disease, SP should be considered as an important support, reducing the net contribution of marital and/or intrapsychic components and improving responsiveness and compliance to medical treatments.

Concerning the psychological intervention, several modes of psychotherapy including cognitive-behavioural therapy, sex therapy, behaviour therapy, educational intervention, and other psychotherapies, which include

\begin{tabular}{|c|c|c|c|c|c|}
\hline Groups & & $\mathbf{I}$ & II & III & IV \\
\hline \multirow{2}{*}{$\begin{array}{l}\text { Treatment group } \\
(n=30)\end{array}$} & Before treatment & 6 & 13 & 11 & 0 \\
\hline & After treatment & 1 & 2 & 21 & 6 \\
\hline \multirow{2}{*}{$\begin{array}{l}\text { Control group } \\
(n=33)\end{array}$} & Before treatment & 8 & 14 & 11 & 0 \\
\hline & After treatment & 4 & 4 & 23 & $2^{*}$ \\
\hline
\end{tabular}

${ }^{*} \mathrm{P}_{\mathrm{EHS}}=0.041$.

EHS, Erection Hardness Score. mindfulness meditation, hypnotherapy and rational emotive therapy have been developed. In the treatment of ED, the unique value of psychodynamic psychotherapy is far more than the improvement of symptoms. Psychodynamic psychotherapy works on the symptoms, and explores the emotional conflicts, defence mechanisms, developmental deficits and personality structure underlying the symptoms to work through them. Contemporary psychoanalysis has evolved drastically away from sexuality. Today, five psychologies of psychoanalysis have been employed in the psychodynamic understanding of patients. They are the theory of drive and emotional conflicts, the theory of ego, superego and ego ideal functions, the theory of narcissism and self-psychology, object relationship theory and attachment theory. These theories have enriched the clinical thinking and methods of traditional psychodynamic therapy.

SP should be fulfilled throughout the course of treatment and may be given alone or in combination with other therapies. ${ }^{17}$ Therefore, this study adopted a combination of BPP with Viagra in the treatment of nonorganic ED. Compared with LTPP, BPP is characterised as brief, goal focused (symptom relief and a certain degree of personality change) and placing importance on client initiative (guiding patients to keep the theme in focus). This therapy focuses more on the role of the focal conflict in the treatment and works around it. The focal conflict consists of three parts: wish, response from the others and response from the self. In short, it is the main problem of the patient. During the treatment, more attention should be paid to the focal conflict and working around it. The so-called focal conflict is simply the crux of the patient's main problem. In clinical work, we should try not to rely on free association, and focus instead on related causes, early life experiences and behaviour patterns to find the focal conflict. Or techniques such as dream interpretation and transference analysis can be used. These are characteristic of BPP, and let patients find out the focal conflict. Time-limitedness and structural settings are another features of BPP. Compared with LTPP, which relies on the loose arrangement of free association and the treatment lasting 6 months to several years, BPP generally lasts about 2-3 months. The frequency of counselling sessions at least twice a week ensures the effectiveness of treatment, and the clinical objectives are well defined in the treatment 
phases. In the first stage (lasting one to three sessions), the therapist generally puts emphasis on the universality of the theme pattern in the patient's life. In the second stage (lasting 14-18 sessions), the focus is on the workingthrough this pattern. In the third stage (the final one to three sessions), the therapy is focused on termination and separation. ${ }^{18}{ }^{19}$ Because the treatment time and effect are controlled and expected, it is suitable for clinical research in psychology. Of course, due to the limitation of the duration of treatment, the treatment process focuses on the change of a certain problem, and the lack of emphasis on extensive personality analysis is also its main disadvantage. The subject of this study, sex, is very complex. It means a great deal to the overall shaping of personality and is premised on ego strength, stability and tolerance. For psychologists, sexual function is not simply the hyperaemia, swelling, pleasure and excretion of an organ after stimulation; nor is sex simply mechanical. As the subject of sex, it also calls for the necessity to deal with the closeness, empathy and self-confidence. ${ }^{20-22}$ From the perspective of object relations, ${ }^{23-25}$ sex can be the object to control the relationship, in which the adjustment of sexual contact presents the possibility of superiority, which means power struggle or passive aggression. Therefore, for men, especially Chinese men, who are generally regarded as the dominant party of sexual activity in eastern cultures, sex is not simply the erectile function of the penis, but also a reflection and reference of power, social status, dominant relationship, personal dignity, male charm, and so on. Sex has a deeper meaning in the nature of unconscious fantasy, including ambition, attachment, intimacy, gender identity, aggression, hostility, and so on. Contemporary psychoanalysis provides clinicians with complex insights into ED. The essence of psychodynamic psychotherapy is to explore the aspects that are not yet fully understood, particularly their performance and potential impact in the occasional therapeutic relationship. ${ }^{26}{ }^{27}$ Seven features of process and technique reliably distinguished psychodynamic therapy from other therapies. They are focused on affect and expression of emotion, exploration of defence mechanisms and resistance, identification of recurring themes and patterns, discussion of past experience, focus on interpersonal relations, focus on the therapy relationship and exploration of fantasy life.

The author gradually realised that lack of intimacy, fear of castration, covert punishment and obstruction of fusion were the main focal conflicts in the psychodynamic level of ED from the summarising of the treatment process and previous experience. Often based on this, ED can be improved directly or indirectly (increasing clinical drug efficacy). ${ }^{28-30}$ As both a clinician and a psychotherapist, the author innovatively used an innovative BPP combined with sildenafil on demand for ED treatment, making significant achievements.

\section{Limitations}

First of all, we did not enroll a large number of cases in this study due to the lack of funds and some patients declined to participate in this study. In addition, as the study involved patients' privacy, many participants discontinued during the treatment. Therefore, there are inevitably some deviations and deficiencies in this study.

Second, this experiment is divided into groups according to the patients' individual treatment wishes. Although the patients' marital status is the same (all of them are married), factors such as cardiovascular disease and infectious disease were excluded, and bad habits such as alcohol and tobacco use were inquired about (two in the treatment group and three in the control group have a history of smoking, no one had long-term alcohol and other substance dependence history), and the age and course of the patients in the treatment group and the control group were generally the same.

Third, due to the limitation of experimental funds and time conditions, the patients with partial abscission mentioned in the general data are not reflected in table 1 , and there may be bias in the complete analysis.

Finally, because there is no special training, qualification assessment and treatment manual for BPP in China, the treatment of these patients was mainly based on the content of BPP in the practice guide of short-term dynamic psychotherapy and other relevant domestic literature. $^{18}$

\section{Implications}

Sildenafil, an inhibitor of cyclic guanosine monophosphate (c-GMP)-specific PDE5 degrading c-GMP, increases intracellular c-GMP concentration by inhibiting PDE5, causes smooth muscle relaxation, which increases the arterial blood flow in the corpus cavernosum, and then promotes penile erection. Although sildenafil has been well recognised for ED, still about $20 \%-30 \%$ patients with ED do not adequately respond to sildenafil (especially patients with psychological impotency). ${ }^{31}$ The addition of adjuvant (androgen) to sildenafil-ineffective patients can improve the therapeutic effects, but there are several adverse reactions such as liver and kidney damage, dependence and high incidence of reproductive system tumours. Therefore, in recent years, studies on adjuvant therapies for ED have gained much attention. Among non-organic $\mathrm{ED}$, psychological ED is the largest source accounting for more than half of the clinical cases. ${ }^{6}$ Thus, psychotherapy is a common treatment for ED. Psychoanalysis differs from other psychotherapeutic orientations in the sense that it is a cure by making people conscious about their unconscious abilities involving their history. Psychologists can solve the problems rooted in the unconscious mind. In other words, psychoanalysis can solve symptoms on the surface, essentially combing the whole spiritual history of human beings, reaching the symptoms of direct confrontation and reconstructing the self-renewal of personality. ${ }^{32} 33$ To reconcile inner conflicts, not only to satisfy material pursuits, people seek psychoanalysis to realise their spiritual values. Psychoanalytic orientation often has a good effect on sexual dysfunction which is irreplaceable to other therapies. Freud, who claimed that 
a person, from birth to late life, had sexual colour in all behavioural motives, was subject to the impulse of sexual instinct, first proposing pansexualism at the beginning of psychoanalytic theory. The occurrence of neurosis is the result of the dissatisfaction or suppression of the sexual instinct impulse. Psychoanalytic theory states that there is a strong motivation behind sexual desire, which drives people to pursue pleasure. This is known as libido, also known as sex drive. The development of libido is divided into: the oral period, anal period, genital period, incubation period and reproductive period. Therefore, using psychoanalytic motivational listening therapy techniques such as free association is possible to understand the sexual experience and experience of the patient in childhood. This helps to find out the 'sexual problem' and 'privacy' that the patient has forgotten and found hard to talk about. 'Privacy' means something in the patient's heart of hearts that is not expressed in the usual therapy such as the handling of previous interpersonal relationships, childhood shadows, history of bullying, or past events which engender negative emotion, and these things may cause mental illness and affect erectile function. The outcomes of psychoanalytic therapy gradually unfold. These outcomes are encouraging clients to surmount 'resistance', to analyse 'transference' and to find 'crux', in order to help patients further 'interpret', 'clarify' and ' work through' and so on. That is the key to determining the success or failure of psychoanalytic psychotherapy. ${ }^{931}$ These outcomes are difficult to achieve using other psychotherapeutic methods, even if they are effective for the moment. ${ }^{32}$ As the famous psychologist $\mathrm{Li}$ Ming said: "It was a relatively long process to achieve a person's growth through psychoanalysis, and to a certain extent it was painful. At the same time, it was a process full of joy and of moving towards the true self by being clearer to ourselves." The BPP used in this study, which differs from traditional LTPP, emphasises the change of a certain problem more efficiently. It does not pursue the deep excavation of the conflicts within the patient's personality, but to deal with the psychodynamic characteristics caused by ED, which makes the problem more prominent by focusing on the effects of the problem. ${ }^{33}$

This study indicated that BPP combined with sildenafil significantly improved the clinical symptoms of patients with non-organic ED, and the improvement with combined treatment was more significant than with sildenafil alone (optimal efficiency $=19 \%>10 \%$ ). In addition, the improvement of the drug combined with psychodynamic psychotherapy was significantly better than the control group $\left(\mathrm{P}_{\text {IIEF }}=0.040, \mathrm{P}_{\mathrm{SAS}}=0.006, \mathrm{P}_{\mathrm{SS}}=0.045\right.$, $\mathrm{P}_{\mathrm{EHS}}=0.041$ ).

The observations suggest that the combination of drug with BPP is superior to drug alone in the treatment of non-organic ED. The method is safe and effective, and has certain clinical promotion value.

Acknowledgements I would like to express my gratitude to all those who have helped me during the writing of this thesis. I gratefully acknowledge the help of Lei
Chen. I do appreciate her patience, encouragement and professional instructions during my thesis writing. Also, I would like to thank Mr Hongwen Cao, who kindly gave me a hand when I was making the questionnaire among the college English learners. Last, but not the least, my gratitude also extends to my family who have been assisting, supporting and caring for me all of my life.

Contributors ZZ, XG: mainly responsible for writing the thesis. YZ: responsible for data collection. CY: responsible for research design and finalisation. JP, LY, YZ: responsible for literature retrieval.

Funding Science and Technology Commission of Shanghai Municipality (Award No: 18401904400).

Competing interests None declared.

Patient consent for publication Obtained.

Ethics approval This trial was approved by the ethical review of the China Academy of Chinese Medical Sciences (WI 128601).

Provenance and peer review Not commissioned; externally peer reviewed.

Data availability statement Data are available upon reasonable request. Data refers to the patient's identity information such as name, age, address, IIEF-5,SAS, etc. But at the beginning of the trial, most of the participants made it clear that they refused to disclose their private information such as name. The statistical data of patients can be obtained from the author of the communication through the mailbox. The data can be reused after getting the patient's consent again.

Open access This is an open access article distributed in accordance with the Creative Commons Attribution Non Commercial (CC BY-NC 4.0) license, which permits others to distribute, remix, adapt, build upon this work non-commercially, and license their derivative works on different terms, provided the original work is properly cited, appropriate credit is given, any changes made indicated, and the use is non-commercial. See: http://creativecommons.org/licenses/by-nc/4.0/.

\section{REFERENCES}

1 Kaufman JM, Vermunlen A. Androgens and mals senescence[M]// Nieschlag E, Behre HM.Testosterone : action, deficiency, substitution. 437. Berlin: Springer, 1998.

2 Hatzimouratidis K, Giuliano F, Moncada I, et al. EAU guidelines on male sexual dysfunction[M. Arnhem: EAU Guidelines Office, 2018.

3 Jichuan Z. Guidelines for the andrology diagnosis and treatment of erectile dysfunction. Renminweishengchubanshe 2013;57:71-8. Chinese.

4 Xueqian L, Heqian Y. Cognitive behavioral therapy and efficacy evaluation of psychogenic erectile dysfunction[J]. Zhongguoxinliweishenzazhi 1990;4:97-101. Chinese.

5 Feldman HA, Goldstein I, Hatzichristou DG, et al. Impotence and its medical and psychosocial correlates: results of the Massachusetts male aging study. J Urol 1994;151:54-61.

6 Habib Davanloo B. Basic principles and techniques in short - term dynamic psychotherapy. Northvale,New Jersey: Jason Aronson Inc: 9-32.

7 Thoma H, Kachele H. Psy-choanalytic practice. Berline: SpringerVerlag: 81-93.

8 American Psyehiattic Association. Diagnostic Criteria from DSM-IV[M. Washington, DC: American Psychiatric Publishing, 1994: 236-7.

9 Xianchen L, Maoqin T, Kun C, et al. Factor ANALYSISOF self-rating anxiety scale. Shandongyikedaxuexuebao 1995;12. Chinese.

10 Jichuan $Z$. The guidance of erectile dysfunction. Zhongguonankexuezazhi 2004;18:68-72. Chinese.

11 Goldstein I, Lue TF, Padma-Nathan H, et al. Oral sildenafil in the treatment of erectile dysfunction. Sildenafil Study Group. N Engl J Med 1998;338:1397-404.

12 Porst $\mathrm{H}$, Gacci M, Büttner $\mathrm{H}$, et al. Tadalafil once daily in men with erectile dysfunction: an integrated analysis of data obtained from 1913 patients from six randomized, double-blind, placebo-controlled, clinical studies. Eur Urol 2014;65:455-64.

13 Buvat J, Hatzichristou D, Boess FG, et al. Continuation and effectiveness of tadalafil once daily during a 6-month observational study in erectile dysfunction: the EDATE study. Int $J$ Clin Pract 2014;68:1087-99.

14 Rubio-Aurioles E, Kim ED, Rosen RC, et al. Impact on erectile function and sexual quality of life of couples: a double-blind, randomized, placebo-controlled trial of tadalafil taken once daily. $J$ Sex Med 2009;6:1314-23. 
15 Huang Y-P, Zheng F-F, Yao F-J, et al. [Daily medication of low-dose tadalafil improves endothelial function and erectile hardness of ED patients]. Zhonghua Nan Ke Xue 2010;16:1052-5. Chinese.

16 Rosen RC. Management of complicated and treatment-refractory ED: clinical issues and guidelines. Int J Impot Res 2000;12 Suppl 3:S59-60.

17 Srini VS, Veerachari SB. Erectile dysfunction shock wave therapy. A new modality in the management of erectile dysfunction: does it improve the outcome? J Mens health 2011;8:213.

18 Book HE. Practice guide to short range dynamic orientation psychotherapy - core conflict theme therapy. Zhongguoqinggongyechubanshe 2017;5. Chinese.

19 Dewan MJ. The art and science of short - range psychotherapy - a clinical guide. Renminweishengchubanshe 2010;5. Chinese.

20 Berry MD, Berry PD, Michael D. Berry etc. Contemporary treatment of sexual dysfunction: reexamining the biopsychosocial model. J Sex Med 2013;10:2627-43.

21 Emanu JC. Psychotherapeutic Treatments for Male and Female Sexual Dysfunction Disorders. In: David D, Lynn SJ, Montgomery $\mathrm{GH}$, eds. Evidence-Based psychotherapy: the state of the science and practice. First Edition. JohnWiley \& Sons, Inc, 2018.

22 Berry MD. The history and evolution of sex therapy and its relationship to psychoanalysis. Int J Appl Psychoanal Stud

23 Fonagy P. Attachment theory and psychoanalysis. Shijietushuchubangongsi 2017;12. Chinese.
24 Green V. Emotional development in psychoanalysis, attachment theory, and neuroscience - creating connections. Zhongguoqinggongyechubanshe 2019;6. Chinese.

25 Scharff DE. Object relationship view of sex and family. Shijietushuchubangongsi 2009;9. Chinese.

26 Shedler J. The efficacy of psychodynamic psychotherapy. Am Psychol 2010;65:98-109.

27 Allan Abbass,etc. Short-Term Psychodynamic psychotherapy for somatic disorders.

28 Simopoulos EF, Trinidad AC. Male erectile dysfunction: integrating psychopharmacology and psychotherapy. Gen Hosp Psychiatry 2013;35:33-8.

29 Almas E. Non-Pharmacological treatment of sexual problems. A review of research literature 1970-2008. Sex ologies 2010;19:202-11.

30 Schmidt HM, Munder T, Gerger H, et al. Combination of psychological intervention and phosphodiesterase-5 inhibitors for erectile dysfunction: a narrative review and meta-analysis. J Sex Med 2014;11:1376-91.

31 Male science branch of Chinese medical association. Diagnosis and treatment guidelines and expert consensus for male diseases in China [M. Beijing: Renminweishengchubanshe, 2016: 64.

32 McWilliams N. Psychoanalytic treatment [M] Zhongguoqinggongyechubanshe 2015;2:54-5. Chinese.

33 Jianlin J. Brief psychodynamic psychotherapy[J]. Zhongguolinchuangxinlixuezazhi 1996;4:243-5. Chinese.

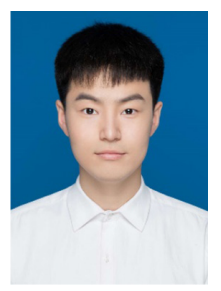

Zhihang Zhang is a second year master's student at Shanghai University of Traditional Chinese Medicine, Shanghai, China. He obtained a bachelor's degree from Henan University of Traditional Chinese Medicine in 2018. He has been working as a resident physician in the department of urology at Longhua Hospital Shanghai University of Traditional Chinese Medicine, Shanghai, China since 2018. His main research interests include using the Integrated traditional Chinese and western medicine in the treatment of male urology diseases and improving the physical and mental health of patients.

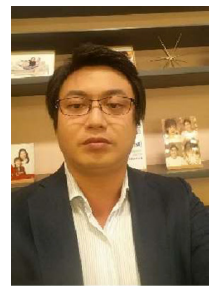

Xiang Gao, who has studied psychological counseling since 2011. He obtained a bachelor's degree from East China Normal University in Shanghai, China in 2019. He has been working as a psychological consultant at psychological counseling studio of East China Normal University in Shanghai, China since 2012. In addition, he is currently a member of the psychological intervention association. His main research areas include marriage and personal growth counseling. 